\title{
Elaboração e aplicação de um Dominó Químico para o auxílio no aprendizado de Distribuição Eletrônica
}

\section{Chemical Domino elaboration and application to aid in the learning Electronic}

\section{Distribution}

Elaboración y aplicación de un Dominó Químico para ayudar en el aprendizaje de la Distribución Electrónica

Recebido: 12/05/2020 | Revisado: 14/05/2020 | Aceito: 17/05/2020 | Publicado: 30/05/2020

\author{
Skarllathy Jennifher Julia Castro de Carvalho \\ ORCID: https://orcid.org/0000-0002-2316-5591 \\ Universidade Federal do Espírito Santo, Brasil \\ E-mail: skarllathy.j@hotmail.com \\ Leila Aley Tavares \\ ORCID: https://orcid.org/0000-0003-1277-9667 \\ Universidade Federal do Espírito Santo, Brasil \\ E-mail: leilaley@yahoo.com
}

\section{Resumo}

A aprendizagem dos conteúdos de Distribuição Eletrônica e Tabela Periódica, muitas vezes, é tida como um processo difícil pelos alunos de Ensino Médio. Diante disso, a proposta deste trabalho foi elaborar e aplicar, em turmas do Ensino Médio, um jogo didático que aborda o conteúdo de Distribuição Eletrônica. A pesquisa foi desenvolvida em três escolas públicas da cidade de São Mateus/ES e teve a finalidade de verificar se a utilização desta metodologia motiva o aluno a alcançar o aprendizado. Como forma de avaliação da metodologia foram aplicados dois questionários; um antes e outro após a dinâmica com o dominó químico. Os resultados demonstraram êxito da proposta, uma vez que foi bem aceita pelos estudantes, os quais participaram de forma lúdica e ativamente do processo de construção dos conceitos relacionados à Distribuição Eletrônica.

Palavras-chave: Ensino de química; Jogo didático; Distribuição eletrônica; Ensinoaprendizagem. 


\begin{abstract}
Learning the contents of Electronic Distribution and Periodic Table is often considered a difficult process by high school students. Therefore, the purpose of this work was to develop and apply, in high school classes, a didactic game that includes the Electronic Distribution content. The research was developed in three public schools in São Mateus/ES city and had the purpose to verify if the use of this methodology motivates the students achieve learning. As a way of evaluating the methodology, two questionnaires were applied: one before and one after the dynamic class using chemical domino. The results demonstrated the proposal success since it was well accepted by the students. They participated in a playful and active way in the construction process of the concepts related to Electronic Distribution.
\end{abstract}

Keywords: Chemistry teaching; Didactic game; Electronic distribution; Teaching and learning.

\title{
Resumen
}

El aprendizaje de los contenidos de Distribución Electrónica y Tabla Periódica, muchas veces, es considerado como un proceso difícil por los alumnos de Enseñanza Media. Ante eso, la propuesta de este trabajo fue elaborar y aplicar, en clases de secundaria, un juego didáctico que aborda el contenido de Distribución Electrónica. La investigación fue desarrollada en tres escuelas públicas de la ciudad de São Mateus/ES y tuvo la finalidad de verificar si el uso de esta metodología motiva al alumno a alcanzar el aprendizaje. Como forma de evaluación de la metodología se aplicaron dos cuestionarios: uno antes y otro después de la dinámica con el dominó químico. Los resultados demostraron éxito de la propuesta, ya que fue bien aceptada por los estudiantes, quienes participaron de forma lúdica y activamente en el proceso de construcción de los conceptos relacionados con la Distribución Electrónica.

Palabras clave: Enseñanza de química; Juego didáctico; Distribución electrónica; Enseñanza-aprendizaje.

\section{Introdução}

A disciplina de química, no Ensino Médio, visa o estudo dos materiais e das substâncias, sobretudo de suas constituições, propriedades e transformações. O conhecimento químico oferece ao aluno subsídios fundamentais para que ele seja capaz de reconhecer os diversos tipos de materiais encontrados no seu cotidiano, bem como compreender as 
transformações químicas envolvidas nos processos naturais, industriais, agrícolas e tecnológicos. Esta ciência contribui para o desenvolvimento de conhecimentos no aluno que o auxiliam em sua interação com o meio em que vive. Assim, um bom aprendizado nessa área é fundamental para que possamos ter uma sociedade mais crítica e com melhor compreensão do mundo e, principalmente, que possa relacionar e aplicar seus conhecimentos no dia a dia seja no supermercado (alimentos), na farmácia (remédios), em casa (utensílios) ou na rua (combustíveis, propaganda, meio ambiente etc).

Um estudo realizado por Mancilha et al (2004) demonstrou que os alunos do Ensino Médio possuem dificuldades em compreender os fenômenos químicos. Estas, por sua vez, repousam principalmente nas limitações do processo ensino-aprendizagem, que falha na hora de estimular a curiosidade dos educandos para compreenderem a dimensão da disciplina na prática e na vivência de sua realidade no cotidiano. No âmbito da escola tradicional, os professores não têm o hábito de variar as metodologias de ensino já estabelecidas. Para Rosa e Rossi (2008) e Brasil (2006) a busca por novas metodologias e estratégias de ensino para a motivação da aprendizagem, que sejam acessíveis, modernas e de baixo custo, é sempre um desafio para os professores.

Os jogos didáticos surgem como uma alternativa, pois incentivam o trabalho em equipe e a interação aluno-professor; auxiliam no desenvolvimento de raciocínio e habilidades; e facilitam o aprendizado de conceitos (Vygotsky, 1989). Essa estratégia para auxiliar na construção do conhecimento vem se tornando cada vez mais popular, como pode ser visto pelo aumento de artigos científicos publicados na área (Almeida et al., 2017; Bürger \& Ghisleni, 2019).

Nesse contexto, o presente trabalho foi realizado com o intuito de elaborar um jogo de Química, aplicá-lo em turmas de três escolas estaduais, e verificar a receptividade dos alunos com relação a essa metodologia e sua ação motivadora na aprendizagem.

\section{Jogos como Proposta de Ensino}

Campos et al (2003) acreditam que a apropriação e a aprendizagem significativa são facilitadas quando o conteúdo toma a forma de atividade lúdica, pois essa proporciona uma maneira mais interativa e divertida de aprendizado, além de possibilitar a proatividade do aluno.

Dentre as atividades lúdicas aplicadas ao ensino destacam-se os jogos educativos. Estes são utilizados com o objetivo de estimular a significação do aprendizado, visto que a 
escola deve manter os alunos em situações de constante aprendizado. De acordo com Antunes (1998) o jogo é uma das atividades que mais estimula a inteligência e também o comportamento social, pois ele impõe regras e faz com que os jogadores controlem seus impulsos, desenvolva e enriqueça suas personalidades.

Segundo Dallabona e Mendes (2004):

[...] brincando, o sujeito aumenta a sua independência, estimula a sua sensibilidade visual e auditiva, valoriza a sua cultura popular, desenvolve habilidades motoras, exercita sua imaginação, sua criatividade, socializa-se, interage, reequilibra-se, recicla suas emoções, sua necessidade de conhecer e reinventar e, assim, constrói seus conhecimentos.

A principal importância do jogo educativo é quando aprender se torna divertido, como afirma Lopes (2001):

É muito mais eficiente aprender por meio de jogos e, isso é válido para todas as idades, desde o maternal até a fase adulta. O jogo em si, possui componentes do cotidiano e o envolvimento desperta o interesse do aprendiz, que se torna sujeito ativo do processo, e a confecção dos próprios jogos é ainda muito mais emocionante do que apenas jogar.

Quando a aprendizagem se torna divertida, o interesse dos alunos em aprender pode ser despertado com mais facilidade, e com isso garantir a satisfação e a permanência desse aluno na escola (Almeida, 2003).

De acordo com Kishimoto (1996), se o professor utilizar os jogos adequadamente, este pode servir para que os alunos fiquem motivados, pois querem jogar bem e, dessa forma, se empenham mais em superar seus obstáculos cognitivos e emocionais. Dessa forma, segundo Ramos (2003), os jogos possibilitam ao educador um melhor rendimento escolar alcançado de forma dinâmica através do brincar.

\section{Distribuição Eletrônica dos Elementos Químicos no Ensino Médio}

A Distribuição Eletrônica é um tema da disciplina de Química que é trabalhado no $1^{\circ}$ ano do Ensino Médio. Nela estuda-se a forma em que os elétrons estão distribuídos nas camadas ou níveis de energia que ficam ao redor do núcleo do átomo. Este conteúdo apresenta grande relevância, pois através da distribuição eletrônica de um elemento químico consegue-se descobrir o número atômico deste, evidenciar a camada de valência e nos permite 
descobrir a quantidade de ligações que esse elemento fará para adquirir sua estabilidade. Dessa forma, este se torna a base para o entendimento de outros importantes conteúdos, na química, como propriedades periódicas (eletronegatividade, raio atômico, afinidade eletrônica) e ligação química.

No entanto, é observada grande dificuldade por parte dos alunos na aprendizagem deste tema. Assim, viu-se uma oportunidade para o desenvolvimento de um jogo didático para o ensino de Distribuição Eletrônica. De acordo com Santos (2018), utilizar temas considerados complexos pelos discentes, de forma mais prática através da construção lúdica, pode despertar o senso crítico e a interação social favorecendo uma melhor absorção de conhecimento. Além disso, fornece uma forma de transmitir o assunto de maneira harmoniosa e proveitosa, despertando no educando habilidades que até então não se conheciam.

\section{Metodologia}

As pesquisas são realizadas na sociedade para trazer novo ou novos saberes como preconiza Pereira et al. (2018). No presente estudo realiza-se uma pesquisa de natureza qualitativa apoiada em dados quantitativos simples utilizando-se de um jogo elaborado, Dominó Químico. Este foi aplicado em turmas de $1^{\circ}, 2^{\circ}$ e $3^{\circ}$ ano de três escolas estaduais do município de São Mateus/ES: Escola Estadual de Ensino Fundamental e Médio (EEEFM) Marita Motta, EEEFM Santo Antônio e Escola Estadual de Ensino Médio (EEEM) Wallace Castelo Dutra. O Dominó Químico foi aplicado às turmas de $2^{\circ}$ e $3^{\circ}$ ano para saber o quanto esses alunos se recordavam do conteúdo visto no $1^{\circ}$ ano, e, verificar qual o tipo de metodologia foi utilizado.

No decorrer da pesquisa foram utilizados como procedimentos metodológicos: dois questionários, aula expositiva e o Dominó Químico. Antes da aplicação do jogo os alunos responderam a um pré-questionário. Em seguida, explicou-se brevemente o conteúdo de Distribuição Eletrônica, fez-se a aplicação do jogo e, por fim, os alunos responderam a um pós-questionário.

Os questionários envolveram questões objetivas e discursivas. As respostas às primeiras foram analisadas aplicando-se estatística descritiva, enquanto às segundas foi realizada a análise de conteúdo de Bardin.

De acordo com Bardin (2011) esse método se configura em: 
Um conjunto de técnicas de análise das comunicações visando a obter, por procedimentos sistemáticos e objetivos de descrição do conteúdo das mensagens, indicadores (quantitativos ou não) que permitam a inferência de conhecimentos relativos às condições de produção/recepção (variáveis inferidas) destas mensagens.

\subsection{Confecção e regras do jogo}

As peças foram criadas em material de papelão nas dimensões 6,5 x 3,0 (cm). Em seguida foram encapadas com papel, e por cima destas colaram-se as peças impressas. Por fim, encapou-se a peça com papel contact transparente (Figura 1).

Figura 1 - Cinco peças do jogo Dominó Químico.

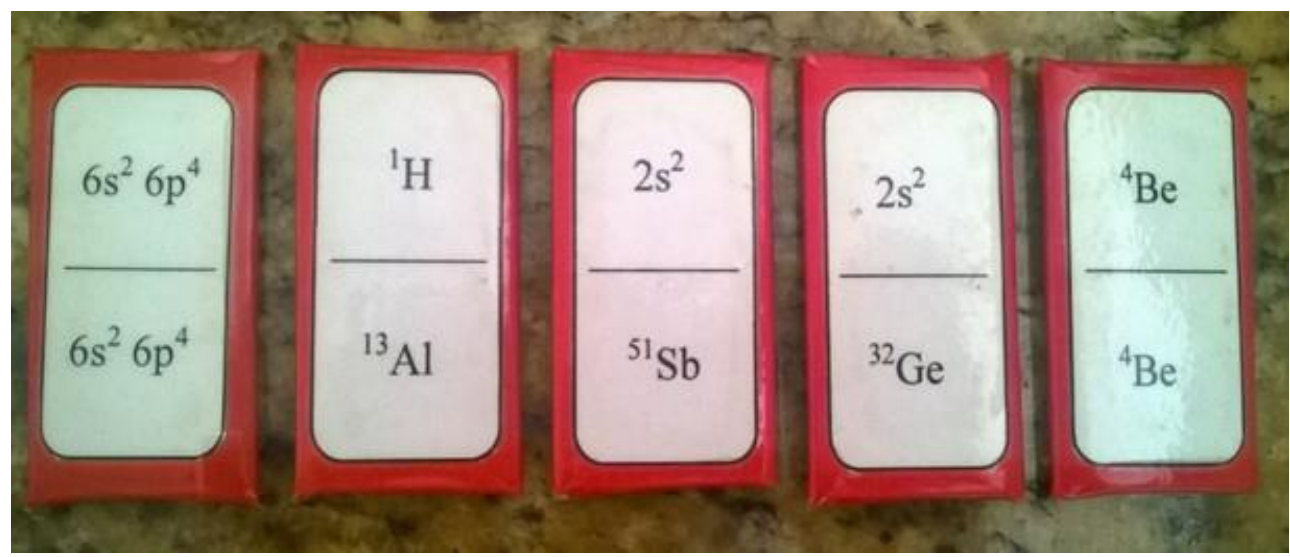

Fonte: os autores.

O jogo didático foi criado de acordo com as regras de um dominó tradicional, sendo no total 28 peças. Portanto, cada jogo continha sete elementos da Tabela Periódica, o que limitou em quatro o número máximo de jogadores. Como muitas turmas possuíam mais de 30 alunos foram elaborados nove jogos de dominó. Estes foram devidamente separados em sacolinhas de TNT e identificados como "Dominó 1, 2, 3 até o 9".

As peças foram confeccionadas de forma a possuir o símbolo do elemento químico com o seu número atômico e a configuração da camada de valência de outro elemento químico. Assim, como regra, os jogadores deveriam ligar o elemento com a sua configuração da camada de valência, não sendo permitido ligar símbolo com outro símbolo igual (Figura 2). 
Figura 2 - Ilustrando a regra do jogo.

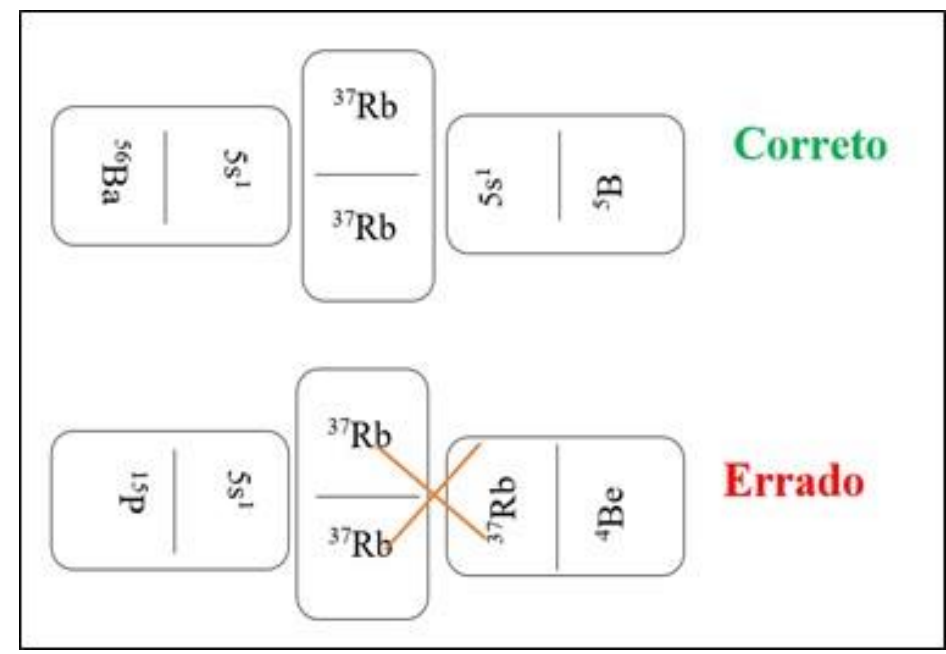

Fonte: Elaborado pelos autores.

Com cada dominó foi impressa uma Tabela Periódica contendo informações suficientes para os alunos executarem a atividade. No verso da Tabela foram colocadas informações (propriedades e utilidades) a respeito de cada elemento abordado. Além disso, também foi entregue aos alunos uma ficha de instruções.

Vale ressaltar que os nove jogos confeccionados não eram idênticos, sendo abordados diferentes elementos químicos em cada. Dessa forma, estes poderiam ser trocados entre os alunos a fim de ampliar os conhecimentos sobre um número maior de elementos.

Como regra, um jogador ficava com sete peças e aquele que tirasse a bucha (peça contendo dois símbolos de um mesmo elemento) iniciava a partida. Cada jogo continha na ficha de instruções a sua bucha especificada.

Após colocar a bucha na mesa, o próximo jogador dava sequência adicionando uma peça que continha a configuração da camada de valência do elemento, se o jogador não tivesse nenhuma peça que continha a configuração, ele passava a vez. O ganhador seria aquele que primeiro terminasse suas peças, ou ficasse com menos peças em mãos ao final da partida.

O objetivo do jogo foi fazer com que os alunos aprendessem associar a camada de valência do elemento com a sua localização na Tabela Periódica. Sendo esse ponto discutido pelo professor no momento da atividade. 


\section{Resultados e Discussão}

A pesquisa contou com a participação de 327 alunos do Ensino Médio, sendo 186 da EEEFM Marita Motta, 81 da EEEFM Santo Antônio e 60 da EEEM Wallace C. Dutra.

Nas três escolas, alunos de $1^{\circ}, 2^{\circ}$ e $3^{\circ}$ ano participaram respondendo aos questionários. O pré-questionário foi aplicado no sentido de saber quais os conhecimentos prévios que eles possuíam. Segundo Gameleira e Bizerra (2019), identificar os conhecimentos "comuns" dos estudantes e relacioná-los com o conhecimento científico é um meio seguro de proporcionar uma aprendizagem significativa, mas também se constitui um desafio. Assim, para desenvolver um ensino com aprendizagem significativa dos discentes é essencial que o professor busque esse saber.

Após a dinâmica com o dominó químico aplicou-se outro questionário, referido aqui como pós-questionário, que teve o objetivo de avaliar a metodologia proposta. As respostas de "múltipla escolha" em ambos foram analisadas estatisticamente. As respostas "abertas" foram verificadas de acordo com a análise de conteúdo proposta por Bardin (2004), da qual a partir de uma amostragem fez-se a análise por categorias, utilizando-se a investigação dos temas. Essa análise consistiu em uma leitura dos significados mais abstratos e simples determinada pelas condições oferecidas pelo sistema linguístico, e objetivou a descoberta das relações existentes entre o conteúdo do discurso e os aspectos exteriores. Conforme, Bardin (2004) essa técnica permite a compreensão, a utilização e a aplicação de um determinado conteúdo.

\subsection{Avaliação do Pré-questionário}

O pré-questionário foi constituído por cinco perguntas, sendo três de múltipla escolha e duas abertas. A seguir descreve-se os resultados obtidos das respostas dos alunos com relação a cada pergunta.

\section{1) Qual a sua maior dificuldade com relação ao ensino da química?}

Essa questão teve a finalidade de verificar as dificuldades comuns entre os alunos do Ensino Médio com relação ao aprendizado na disciplina de Química. 
As respostas a essa pergunta sugerem que a principal dificuldade dos alunos ocorre devido a metodologia utilizada no processo ensino-aprendizagem, sendo apontada pela maioria dos alunos, de $1^{\circ}, 2^{\circ}$ e $3^{\circ}$ ano, de acordo com a Tabela 1.

Tabela 1 - Dificuldades dos alunos com relação ao Ensino de Química.

\begin{tabular}{|c|c|c|c|}
\hline & \multicolumn{3}{|c|}{ RESPOSTAS DOS ALUNOS (\%) } \\
\hline Opções & $1^{\mathbf{0}}$ ano & $2^{\mathbf{o}}$ ano & $3^{\mathbf{o}}$ ano \\
\hline Metodologia utilizada & 55,9 & 32,8 & 43,3 \\
Falta de interesse pela disciplina & 21,5 & 30,0 & 19,6 \\
Poucos recursos didáticos & 8,6 & 20,4 & 19,6 \\
Disciplina sem aplicação na vida & 8,6 & 10,2 & 5,2 \\
Outras & 5,4 & 6,6 & 12,3 \\
\hline
\end{tabular}

Fonte: os autores.

Outro fator que muitos alunos acreditam contribuir para aumentar as suas dificuldades com relação à disciplina é a falta de interesse destes pela matéria, sendo os do $2^{\circ}$ ano os que mais apontaram esse fator. Possivelmente, porque nesse ano o conteúdo envolve muitas reações químicas e cálculos, o que acaba por desestimular muitos deles. Da mesma forma, um maior número de alunos do $2^{\circ}$ ano $(10,2 \%)$ afirmou que a Química é uma disciplina sem aplicação na vida, pois estes apresentam ainda mais dificuldades em correlacionar o conteúdo estudado com os fatos de seu cotidiano.

Com relação a serem utilizados poucos recursos didáticos, cerca de $20 \%$ dos alunos de $2^{\circ}$ e de $3^{\circ}$ ano disseram ser o motivo de suas dificuldades com relação à disciplina. Já os alunos de $1^{\circ}$ ano, somente $8,6 \%$ concordam com essa resposta.

Outros fatores que também foram lembrados pelos alunos incluem: a não compreensão da matéria, a falta de concentração, a complexidade da disciplina e o (a) professor (a) não explicar bem o conteúdo ou não interagir com a turma.

De acordo com uma pesquisa realizada por Paz et al (2010) sobre a dificuldade encontrada pelos alunos em aprender Química, os autores afirmaram que a metodologia utilizada pelo professor é um motivo marcante para a dificuldade dos alunos em aprender, pois os professores acabam dando ênfase à memorização de fórmulas, priorizando os cálculos e desvalorizando à experimentação e a construção do conhecimento científico dos alunos. 
Assim cabe ao professor variar os seus métodos de ensino visando utilizar outros recursos didáticos e associar os conteúdos com o cotidiano do aluno, a fim de proporcionar uma aprendizagem significativa.

\section{2) Você já teve a oportunidade de assistir aulas nas quais se utilizaram jogos didáticos?}

Essa questão teve o objetivo de conferir o percentual de alunos que já conheciam o método de ensino socializante aplicado neste trabalho. A Tabela 2 resume as respostas dos alunos.

Tabela 2 - Alunos que já assistiram aulas em que se utilizou jogos didáticos.

\begin{tabular}{|c|c|c|c|}
\hline & \multicolumn{3}{|c|}{ RESPOSTAS DOS ALUNOS (\%) } \\
\hline Opções & $1^{\mathbf{o}}$ ano & $2^{\mathbf{o}}$ ano & $3^{\mathbf{o}}$ ano \\
\hline Sim & $24,7 \%$ & $39,4 \%$ & $36,2 \%$ \\
Não & $75,3 \%$ & $60,6 \%$ & $63,8 \%$ \\
\hline
\end{tabular}

Fonte: os autores.

A maioria dos alunos dos três anos do Ensino Médio nunca assistiu aulas em que jogos didáticos tenham sido utilizados como método de ensino. Isso é ainda mais evidente no $1^{\circ}$ ano, em que se observa que 75,3\% dos estudantes nunca assistiram aulas com aplicação desse recurso no processo de ensino-aprendizagem.

Essa questão nos revela que apesar de ser uma metodologia bastante difundida atualmente ela ainda é pouco utilizada pelos professores. Segundo Gomes e Friedrich (2001), muitos professores não a utilizam por desconhecerem os seus benefícios. Outra razão para não a utilizarem é que a elaboração dos jogos demanda muito tempo. Uma forma de contornar esse problema, como sugere Silva e Amaral (2011), seria pedir aos próprios alunos que os criem. 
3) De um grau de 0 a 10, sendo 0 não se lembrar de NADA e 10 se lembrar de TODO conceito passado a você. Qual é o grau de recordação que você possui sobre a “Distribuição eletrônica”?

Essa questão, juntamente com a questão 4, foi elaborada com a finalidade de buscar saber o quanto os alunos tinham de conhecimento prévio sobre o conteúdo. Ou seja, saber o quanto eles se recordavam da teoria trabalhada nas aulas tradicionais que tiveram anteriormente a essa atividade. $\mathrm{Na}$ análise desta questão, dividiu-se as respostas em cinco categorias, e procedeu-se de acordo com a análise de conteúdo de Bardin (2004). A Tabela 3 relaciona as categorias e as respostas dos alunos.

Tabela 3 - Grau de conhecimento de Distribuição Eletrônica por parte dos alunos.

\begin{tabular}{|c|c|c|c|}
\hline & \multicolumn{3}{|c|}{ RESPOSTAS DOS ALUNOS (\%) } \\
\hline Categorias & $1^{\mathbf{o}}$ ano & $2^{\mathbf{o}}$ ano & $3^{\mathbf{o}}$ ano \\
\hline Não responderam nada & 13,3 & 6,7 & 3,3 \\
Grau 0 & 13,3 & 10,0 & 30,0 \\
Grau de 1 a 3 & 16,7 & 16,7 & 10,0 \\
Grau de 4 a 7 & 40,0 & 46,6 & 40,0 \\
Grau de 8 a 10 & 16,7 & 20,0 & 16,7 \\
\hline
\end{tabular}

Fonte: os autores.

A maioria dos alunos dos três anos disse lembrar razoavelmente do conteúdo (grau 4 a 7). Enquanto, uma menor porcentagem afirmou ter uma pequena lembrança (grau 1 a 3 ) ou se lembrar bastante do conteúdo (grau de 8 a 10). Cabe ressaltar que em relação aos alunos de $1^{\circ}$ e $2^{\circ}$ ano, os de $3^{\circ}$ foram os que mais disseram não lembrar nada sobre o conteúdo de distribuição eletrônica, cerca de 30,0\%. Provavelmente, pelo tempo decorrido após estudarem esse conteúdo, o qual é tratado no $1^{\circ}$ ano.

\section{4) Escreva algo que você se lembra sobre Distribuição Eletrônica.}

Essa questão foi elaborada com a finalidade de complementar a questão 3 e verificar se os alunos que dizem se lembrar do conteúdo, realmente se lembram e do que eles se lembram. As respostas foram divididas em oito categorias, e assim analisou-se a frequência 
(CC BY 4.0) | ISSN 2525-3409 | DOI: http://dx.doi.org/10.33448/rsd-v9i7.4453

que cada uma foi citada. A Tabela 4 relaciona as categorias com a sua frequência de aparição nas respostas.

Tabela 4 - Conhecimento dos alunos sobre Distribuição Eletrônica.

\begin{tabular}{|c|c|c|c|}
\hline & \multicolumn{3}{|c|}{ RESPOSTAS DOS ALUNOS (\%) } \\
\hline Categorias & $1^{\mathbf{o}}$ ano & $2^{\mathbf{o}}$ ano & $3^{\mathbf{o}}$ ano \\
\hline Não responderam nada & 25,7 & 24,2 & 40,6 \\
Resposta incoerente com o assunto & 2,9 & 9,1 & 3,1 \\
Distribuição dos elétrons & 34,2 & 9,1 & 9,4 \\
Isóbaros, Isótopos e Isótonos & 8,6 & 0 & 0 \\
Elétrons e Prótons & 2,9 & 6,1 & 6,2 \\
Camadas e subníveis & 22,8 & 21,2 & 18,8 \\
Diagrama de Linus Pauling & 2,9 & 30,3 & 15,7 \\
Localizar o elemento na TP & 0 & 0 & 6,2 \\
\hline
\end{tabular}

Fonte: os autores.

Observa-se que 40,6\% dos alunos do $3^{\circ}$ ano não responderam a essa questão. Isso vem corroborar com as respostas dadas na questão 3, na qual 30\% destes afirmaram ter grau de recordação igual a 0 .

Outro fato que chama atenção é que nenhum aluno de $1^{\circ}$ e $2^{\circ}$ ano mencionou a relação da distribuição eletrônica com a localização do elemento na Tabela Periódica. Sobre essa relação, somente $6,2 \%$ dos alunos de $3^{\circ}$ ano fizeram alusão a ela.

Alguns alunos deram respostas incoerentes com o assunto ou escreveram frases desconexas, como por exemplo a seguinte resposta dada por um aluno de $2^{\circ}$ ano: "Quando o coeficiente de valência é de 1 a 3 tem pretensão a ser prótons, e de 5 a 7 , nêutrons”.

Esta frase mostra que o aluno apresenta um conhecimento confuso e errôneo, indicando que ele não teve uma aprendizagem significativa sobre o conteúdo em questão.

Em oposição, vários alunos apresentaram algum conhecimento sobre Distribuição Eletrônica, onde os temas mais citados foram a presença de camadas e subníveis, a distribuição dos elétrons e a utilização do Diagrama de Linus Pauling. Cerca 8,6\% dos alunos do $1^{\circ}$ ano ainda associaram o assunto com átomos isóbaros, isótopos e isótonos, o que não foi observado por nenhum de $2^{\circ}$ e $3^{\circ}$ ano. Provavelmente, por ter decorrido um tempo maior que estudaram o assunto, não se lembrando dessas definições. Alguns alunos também associaram 
o assunto com o número de elétrons e prótons dos elementos e, que a partir desses é possível fazer a distribuição eletrônica.

\section{5) Qual a metodologia que foi utilizada para o ensino dessa matéria?}

Essa questão foi elaborada com o intuito de averiguar o tipo de metodologia de ensino utilizada pelo professor ao ensinar esse conteúdo para os alunos, e analisar se esta pode influenciar no número de alunos que não conseguiram obter um aprendizado significativo do conteúdo de Distribuição Eletrônica. A Tabela 5 exibe as respostas dos alunos de cada ano do Ensino Médio.

Tabela 5 - Metodologia utilizada para ensinar Distribuição Eletrônica para os alunos.

\begin{tabular}{|c|c|c|c|}
\hline & \multicolumn{3}{|c|}{ RESPOSTAS DOS ALUNOS (\%) } \\
\hline Opções & $1^{\mathbf{o}}$ ano & $2^{\mathbf{o}}$ ano & $3^{\mathbf{o}}$ ano \\
\hline Apenas aula expositiva & 57,0 & 74,4 & 74,5 \\
Aula expositiva e atividades lúdicas & 18,3 & 14,6 & 20,2 \\
Apenas atividades lúdicas & 17,2 & 9,5 & 4,2 \\
Utilização de outras metodologias & 7,5 & 1,5 & 1,1 \\
\hline
\end{tabular}

Fonte: os autores.

Observa-se, de acordo com os alunos de todos os anos, principalmente de $2^{\circ}$ e $3^{\circ}$ que ultrapassam $74 \%$ das respostas, que a metodologia mais utilizada no ensino foi somente aulas expositivas. Em $2^{\circ}$ lugar vem aulas expositivas juntamente com a utilização de atividades lúdicas, em $3^{\circ}$ lugar apenas atividades lúdicas, e por último a utilização de outras metodologias, tais como: aulas de laboratório e utilização de multimídia.

Cabe ressaltar que é função do educador motivar o estudante e decidir quais as melhores maneiras de inserir outras atividades durante as aulas. Sabe-se que nem todos tem facilidade de aprender da mesma forma, assim, torna-se necessário diversificar. Nesse sentido, o jogo se apresenta como mais uma ferramenta dentre as tantas possíveis para estimular e tornar o ensino de química mais lúdico e educativo dentro de uma dinâmica prazerosa para todos os envolvidos. 


\subsection{Avaliação do pós-questionário}

O pós-questionário do Dominó Químico foi constituído por quatro perguntas, sendo três de múltipla escolha e uma aberta. A seguir descreve-se os resultados obtidos das respostas dos alunos com relação a cada pergunta.

\section{1) O que você achou da nova forma de ensinar a disciplina de Química através de jogos}

\section{didáticos?}

Observa-se que a maioria dos alunos gostou da metodologia e a viram como uma forma interessante, motivadora e divertida de aprender Química (Tabela 6). Chama a atenção, que a aceitabilidade da proposta, em cada Ano do Ensino Médio, seja cerca de 98\% ou maior.

Esses resultados condizem com a afirmação de Santana (2008) em que ela afirma que a utilização de atividades lúdicas contribui para o desenvolvimento de competências e habilidades e aumenta a motivação dos alunos perante as aulas de Química e, através dos resultados obtidos em sua pesquisa é concluído que essa metodologia torna mais fácil e dinâmico o processo de ensino-aprendizagem.

Tabela 6 - Opinião dos alunos a respeito da utilização de jogos didáticos.

\begin{tabular}{|c|c|c|c|}
\hline & \multicolumn{3}{|c|}{ RESPOSTAS DOS ALUNOS (\%) } \\
\hline Opções & $1^{\mathbf{o}}$ ano & $2^{\mathbf{o}}$ ano & $3^{\mathbf{0}}$ ano \\
\hline Interessante, motivadora e divertida & 97,7 & 98,3 & 100 \\
Sem muita diferença das aulas comuns & 2,3 & 1,7 & 0 \\
\hline
\end{tabular}

Fonte: os autores.

Deve-se destacar, nesse caso, que a metodologia proposta inclui o jogo educativo como ferramenta complementar, uma vez que antes da aplicação do mesmo foi dada uma revisão dos conteúdos já vistos pelos alunos sobre Distribuição Eletrônica. 


\section{2) O que você achou das regras do jogo aplicado?}

Observa-se, na Tabela 7, que a maioria dos estudantes dos três anos acharam as regras do jogo de fácil entendimento. Essa facilidade apresentou-se de forma crescente para os alunos de $1^{\circ}, 2^{\circ}$ e $3^{\circ}$ ano, refletindo nas porcentagens de suas repostas em 65,$1 ; 74,8$ e $94,6 \%$ respectivamente.

Tabela 7 - Quantidade de alunos que acharam as regras do jogo de fácil entendimento.

\begin{tabular}{|c|c|c|c|}
\hline & \multicolumn{3}{|c|}{ RESPOSTAS DOS ALUNOS (\%) } \\
\hline Opções & $1^{\mathbf{0}}$ ano & $2^{\mathbf{o}}$ ano & $3^{\mathbf{o}}$ ano \\
\hline Fácil entendimento & 65,1 & 74,8 & 94,6 \\
Difícil entendimento & 34,9 & 25,2 & 5,4 \\
\hline
\end{tabular}

Fonte: os autores.

Embora em menor proporção, $34,9 \%$ dos alunos de $1^{\circ}$ ano e $25,2 \%$ de $2^{\circ}$, responderam achar as regras do jogo de difícil entendimento. Essa proporção nos acende um alerta, e nos leva a refletir a necessidade de ocorrer um diálogo entre professores e alunos para juntos discutirem a atividade lúdica a ser realizada. Assim, seria possível observar e avaliar o nível de desenvolvimento dos educandos e diagnosticar as dificuldades individuais, para poder produzir estímulos adequados a cada um numa maior interação com os discentes antes mesmo da elaboração do jogo didático.

Outros autores, como Capri et al (2017), defendem que os próprios alunos confeccionem os jogos educativos. Dessa forma, estes podem construir seu conhecimento por meio da pesquisa dos temas didáticos e da discussão com os colegas para a elaboração e o desenvolvimento dos jogos. Nesse momento ocorrerá a interação do grupo para a construção da proposta. A socialização, nesse caso, também é desenvolvida, uma vez que ocorrerá o êxito na produção final apenas se a troca de ideias e trabalho em equipe for realmente efetiva. De acordo com Coelho e Pisoni (2012), essas trocas entre os parceiros são muito importantes se constituindo em momentos significativos no processo ensino-aprendizagem. 
3) Você gostaria que na sua escola fosse adotado o uso de jogos didáticos para auxiliar no processo de ensino-aprendizagem?

Essa questão foi elaborada com a finalidade de saber se os alunos gostariam que mais jogos didáticos fossem aplicados durante o ensino, e se em outras disciplinas também deveria ser aplicado.

Observou-se, na Tabela 8, que a maioria dos alunos dos três anos do Ensino Médio gostaria que a metodologia fosse adotada na escola. Pelo menos 98,8\% dos alunos de cada ano, veem o jogo como algo positivo e que auxilia em sua aprendizagem.

Tabela 8 - Quantidade de alunos que querem que a metodologia seja adotada em sua escola.

\begin{tabular}{|c|c|c|c|}
\hline & \multicolumn{3}{|c|}{ RESPOSTAS DOS ALUNOS (\%) } \\
\hline Opções & $1^{\mathbf{0}}$ ano & $2^{\mathbf{o}}$ ano & $3^{\mathbf{o}}$ ano \\
\hline Sim & $98,8 \%$ & $99,1 \%$ & $98,9 \%$ \\
Não & $1,2 \%$ & $0,9 \%$ & $1,1 \%$ \\
\hline
\end{tabular}

Fonte: os autores.

\section{4) Quais sugestões você daria para a melhoria do jogo didático aplicado?}

Essa questão foi elaborada com a finalidade de obter as sugestões dos alunos para a melhoria do jogo aplicado.

As respostas foram divididas em nove categorias, e assim analisou-se a frequência com que cada uma foi citada nas respostas. A Tabela 9 relaciona as categorias e as suas frequências nas respostas dos alunos. 
Research, Society and Development, v. 9, n. 7, e562974453, 2020

(CC BY 4.0) | ISSN 2525-3409 | DOI: http://dx.doi.org/10.33448/rsd-v9i7.4453

Tabela 9 - Sugestões feitas pelos alunos para a melhoria do Dominó Químico.

\begin{tabular}{|c|c|c|c|}
\hline & \multicolumn{3}{|c|}{ RESPOSTAS DOS ALUNOS (\%) } \\
\hline Categorias & $1^{\circ}$ ano & $2^{\mathbf{o}}$ ano & $3^{\mathbf{o}}$ ano \\
\hline Não responderam nada & 30,0 & 16,7 & 20,0 \\
Nenhuma sugestão/O jogo está bom & 36,7 & 43,3 & 66,7 \\
Explicar mais/Ser mais fácil & 13,3 & 10,0 & 6,7 \\
Jogos com outros conteúdos/ Aplicar mais jogos & 13,3 & 13,4 & 3,3 \\
Premiar os vencedores & 6,7 & 0 & 0 \\
Aplicar jogos eletrônicos & 0 & 3,3 & 0 \\
Melhorar a Tabela Periódica & 0 & 10,0 & 0 \\
Aumentar o número de jogadores & 0 & 3,3 & 0 \\
Melhorar o designer do jogo & 0 & 0 & 3,3 \\
\hline
\end{tabular}

Fonte: os autores.

De acordo com os dados obtidos, observou-se que a quantidade de alunos que não respondeu nada ou respondeu não ter nenhuma sugestão foi alta, principalmente nas respostas dos alunos do $3^{\circ}$ ano. Ou seja, estes acharam que o jogo estava bom.

Alguns disseram que deveria haver mais explicações antes do jogo e que este deveria ser mais fácil.

Outro grupo de alunos não deram sugestões para a melhoria dos jogos, mas aproveitaram esse espaço para pedir a aplicação de mais jogos em Química e em outras disciplinas.

Uma pequena porcentagem dos alunos do $1^{\circ}$ ano, cerca de $6,7 \%$, apresentaram a sugestão de recompensa ou premiação aos ganhadores do jogo, o que não foi observado nas respostas dos alunos dos outros anos.

Cerca de 3,3\% dos alunos do $2^{\circ}$ ano sugeriram a aplicação de jogos eletrônicos e aumentar o número de jogadores para a execução do jogo e, 10,0\% pediram para melhorar a Tabela Periódica fornecida.

Cerca de $3,3 \%$ dos alunos do $3^{\circ}$ ano sugeriram melhorar o designer das peças e utilizar madeira ao invés de papelão.

Esse retorno é importante, pois se configura num momento de diálogo entre professor e aluno onde este se mostra crítico, participando da elaboração da atividade lúdica e atuando de forma ativa na construção de seu saber. 


\section{Considerações Finais}

Verificou-se que o fato de jogar em sala de aula proporcionou momentos ricos em interação e aprendizagem, auxiliando educadores e educandos no processo. A aplicação do procedimento socializante mostrou que os alunos dos três anos do Ensino Médio se sentiram mais motivados a aprender. Além disso, a interação com os colegas de classe fez com que eles discutissem e indagassem sobre os conteúdos, o que estimula o pensamento crítico e favorece um melhor aprendizado.

Assim, pode-se dizer que a inserção do jogo didático como um recurso complementar no processo ensino-aprendizagem favorece a fixação do conteúdo de forma divertida e descontraída. Isso foi observado também na fala de um aluno, que disse "Nossa, como isso é fácil, agora sim eu entendi”, se referindo à distribuição eletrônica dos elementos.

Assim, ensinar brincando, desde que seja de forma devidamente planejada e adequada, pode ser um método mais eficiente e produtivo do que apenas com os métodos tradicionais.

Como afirma Pereira, Fernandes e Bizerra (2020), o processo de ensino e aprendizagem é complexo e, portanto, exige diversificação de metodologias e participação ativa dos alunos. Dessa forma, entende-se que é necessário mais estudo sobre diferentes metodologias de ensino-aprendizagem e os impactos destas no envolvimento dos estudantes e na construção de seus conhecimentos.

\section{Referências}

Almeida, FD, Amaral, JWR, Pieri, MS \& Mattar, J. (2017). O jogo do método: jogos de tabuleiro como suporte ao ensino da disciplina Metodologia Científica. Research, Society and Development, 6(2), 148-170.

Almeida, PN. (2003). Educação lúdica: Técnicas e jogos pedagógicos. 11.ed. São Paulo: Edições Loyola.

Antunes, C. (1998). Jogos para estimulação das múltiplas inteligências. Rio de Janeiro: Vozes.

Bardin, L. (2004). Análise de conteúdo. Tradução de Luís Antero Reto e Augusto Pinheiro. 3. ed. Lisboa: Edições. 
Brasil. Ministério da Educação. Secretaria de Educação Básica. (2006). Orientações curriculares para o Ensino Médio. Ciências da natureza, matemática e suas tecnologias. Acesso em: 05 março 2020. Disponível em http://portal.mec.gov.br/seb/arquivos/pdf/book_volume_02_internet.pdf.

Bürger, CAC \& Ghisleni, TS. (2019). Educação e jogos: análise educomunicativa sobre a implementação de jogos em ambientes de ensino. Research, Society and Development, 8(4), $1-15$.

Campos, LML, Felicio, AKC \& Bortolotto, TM. (2003). A produção de jogos didáticos para o ensino de ciências e biologia: uma proposta para favorecer a aprendizagem. Núcleos de Ensino da UNESP. Acesso em: 05 março 2020. Disponível em: www.unesp.br/prograd/PDFNE2002/aproducaodejogos.pdf.

Capri, MR, Alves, VO \& Capri Neto, A. (2017). Elaboração de jogos didáticos por alunos do curso de análise instrumental como estratégia didático-pedagógica. In: XLV Congresso Brasileiro de Educação em Engenharia, Joinville/SC. Acesso em: 05 março 2020. Disponível em:

https://www.researchgate.net/publication/322537186_Elaboracao_de_jogos_didaticos_por_al unos_do_curso_de_Analise_Instrumental_como_estrategia_didatico-pedagogica.

Coelho, L \& Pisoni, S. (2012). Vygotsky: sua teoria e influência na educação. Revista Modelos. 2(1), 144-152

Dallabona, SR \& Mendes, SMS. (2004). O lúdico na educação infantil: jogar, brincar, uma forma de educar. Revista de divulgação técnico científica do ICPG, 1(4), 107-112.

Gameleira, ST \& Bizerra, AMC. (2019). Identificação de conhecimentos prévios através de situações-problema. Revista Educação, Cultura e Sociedade. 9(2), 130-147.

Gomes, RR \& Friedrich, M. (2001). A contribuição dos jogos didáticos na aprendizagem de conteúdos de ciências e biologia. In: Encontro Regional de Ensino de Biologia (EREBIO 1), 
Rio de Janeiro. Acesso em: 05 março 2020. Disponível em:

http://regional2.sbenbio.com.br/publicacoes/anais_I_erebio.pdf.

Kishimoto, TM. (1996). O jogo e a educação infantil: jogo, brinquedo, brincadeira e educação. São Paulo: Cortez.

Lopes, MG. (2001). Jogos na educação: criar, fazer, jogar. São Paulo, Cortez.

Mancilha, FS, Finatto, MJB \& Del Pino, JC. (2004). Análise do capítulo ligação química nos manuais didáticos de Química Geral. In: XVI Salão de Iniciação Científica da UFRGS, Porto Alegre. Acesso em 05 março 2020. Disponível em: https://lume.ufrgs.br/handle/10183/54117.

Paz, GL, Neto, COC \& Oliveira, ML. (2010). Dificuldade no ensino-aprendizagem de química no ensino médio em algumas escolas públicas da região sudeste de Teresina. In: $8^{\circ}$ Simpósio Brasileiro de Educação Química, Natal. Acesso em: 05 março 2020. Disponível em: http://www.abq.org.br/simpequi/2010/trabalhos/196-4222.htm.

Pereira, AS et al. (2018). Metodologia da pesquisa científica. [e-book]. Santa Maria. Ed. UAB/NTE/UFSM. Acesso em: 13 maio 2020. Disponível em: https://repositorio.ufsm.br/bitstream/handle/1/15824/Lic_Computacao_MetodologiaPesquisa-Cientifica.pdf?sequence $=1$.

Pereira, AW, Fernandes, PRD \& Bizerra, AMC. (2020). A produção de sabão como recurso pedagógico para o ensino de funções orgânicas. Research, Society and Development, 9(2), 123.

Ramos, JRS. (2003). Dinâmicas, brincadeiras e jogos educativos. Rio de Janeiro: DP \& A.

Rosa, MIP \& Rossi, AV. (2008). Educação Química no Brasil: memórias, políticas e tendências. Campinas: Átomo.

Santana, EM. (2008). A influência de atividades lúdicas na aprendizagem de conceitos químicos. In: I Seminário Nacional de Educação Profissional e Tecnológica (SENEPT), Belo Horizonte. Acesso em: 21 maio 2015. Disponível em: 
http://www.senept.cefetmg.br/galerias/Arquivos_senept/anais/terca_tema1/TerxaTema1Artigo 4.pdf.

Santos, EAC \& Jesus, BC. (2010). O lúdico no processo de ensino-aprendizagem. In: IV

Fórum de Educação e Diversidade, Tangará da Serra. Acesso em: 05 março 2020. Disponível em: http://need.unemat.br/4_forum/artigos/elia.pdf.

Silva, TC \& Amaral, CL. (2011). Jogos e avaliação no processo ensino-aprendizagem: uma relação possível. Revista de ensino de ciência e matemática, 2, 1-8.

Vygotsky, LS. (1989). A formação social da mente. São Paulo: Martins Fontes.

\section{Porcentagem de contribuição de cada autor no manuscrito}

Skarllathy Jennifher Julia Castro de Carvalho - 50\%

$$
\text { Leila Aley Tavares }-50 \%
$$

